\title{
Lead-Lag Relationships in an Embryonic Stock Market: Exploring the Role of Institutional Ownership and Liquidity
}

\author{
Vaalmikki Arjoon \\ (University of the West Indies) \\ Spiros Bougheas* and Chris Milner \\ (University of Nottingham, UK)
}

May, 2014

\begin{abstract}
This paper investigates the influence of institutional ownership and liquidity on stock return relationships for an embryonic and relatively illiquid stock market. Using daily, individual stock data for Trinidad and Tobago from 2001 to 2012 and a VAR modelling approach, we find for firms of all sizes and levels of analyst coverage that the returns of more institutionally favoured stocks lead those with less institutional ownership. Distinctively, greater institutional coverage is shown not to be associated with greater liquidity, though liquidity levels do condition the influence of institutional ownership. This indicates that institutional owners have information advantages relative to other stock owners.
\end{abstract}

JEL Classification: $G 14, G 23$

Key words: Cross autocorrelation, institutions, embryonic market

* Corresponding author: Spiros Bougheas, School of Economics, University of Nottingham, Nottingham, NG7 2RD, UK. Phone: 44115 8466108; Fax: 44115 9514159; email: spiros.bougheas@ @ottingham.ac.uk 


\section{Lead-Lag Relationships in an Embryonic Stock Market: Exploring the Role of Institutional Ownership and Liquidity}

\section{Introduction}

Over the past 30 years, we have learnt a lot about emerging markets finance. The bulk of the research focuses on issues related to the impact of market integration and financial liberalization on asset prices and their relationship to those in developed economies. Out of this line of research we now understand, for example, that emerging markets are relatively inefficient and are characterized by infrequent trading. In these circumstances asset returns are not normally distributed, have high serial correlation and are slow to adjust to current information. ${ }^{1}$ Slow price adjustment has also been documented for prices of both individual stocks and portfolios traded in developed economies. In particular, numerous studies provide evidence of lead-lag effects in cross-autocorrelations of stock returns, strongly suggesting that some stocks react to information faster than other stocks. One explanation offered for these lead-lad effects is variation in institutional ownership between stocks. ${ }^{2}$ Data analyses of stock returns from the New York Stock Exchange (NYSE) provide strong support for this hypothesis (Badrinath et al. 1995; Sias and Starks, 1997; Chuang and Lee, 2011).

Sias and Starks (1997) review various theoretical attempts to explain how the presence of institutional investors affects the behaviour of stock prices. Institutional investors trade in the information they collect and the prices of the corresponding stocks will reflect the information set observed by these investors. While some of this information is stock specific, a portion will be general in nature, and therefore, relevant to the pricing of stocks that are held by non-institutional investors (institutionally, unfavoured stocks). By observing the

\footnotetext{
${ }^{1}$ For reviews of this extensive literature, see Bekaert and Harvey $(2002,2003)$.

${ }^{2}$ Alternative explanations include non-synchronous trading (Lo and MacKinlay, 1990), variations in analyst coverage (Brennan et al. 1993) and variations in liquidity (Chordia and Swaminathan, 2000).
} 
prices of the institutionally favoured stocks, non-institutional investors will find information relevant to the pricing of the rest of the stocks. By trading on this information, they will transmit the informational content from the lagged prices of the institutionally favoured to the current prices of the unfavoured stocks.

This lead-lag, cross-autocorrelation relationship has been empirically investigated in the context of the larger, emerging markets. For instance, Chan and Hameed (2006) use data from Standard \&Poor's (formerly the International Finance Corporation) Emerging Markets Database (EMDB), which covers more than 2000 stocks from 45 emerging markets. The authors find that, after controlling for the influence of firm size on lead-lag relations, the returns of a high analyst-following portfolio lead the returns of a low analyst-following portfolio more than the converse. Similar results were obtained by Boyer and Kumagai, Y (2006) using the same data set to explore contagion and by other studies that focus on singlecountry stock exchanges (Gebka, 2008 for Poland; Xu, Chan, Jiang and Yi, 2013 for China). Further, Bae, Ozoguz, Tanc and Wirjanto (2012) also using the EMDB database assess whether the degree of accessibility of foreign investors to emerging stock markets has a significant influence on the diffusion of global market information across stocks in emerging markets. They show that greater accessibility reduces price delay to global market information. They also find that the returns of highly investible or accessible stocks lead those of non-investible stocks, with highly investible stocks incorporating global information more quickly. The same conclusion is reached by studies of single-country stock exchanges (Lee, Li and Wang, 2010 for China; Park and Chung, 2007 for S. Korea) and stock index futures (Bohl, Salm and Schuppli, 2011 for Poland). In contrast, Chan, Menkveld, and Yang (2007) also studying the Chinese market find that lead-lag effects are likely to capture private local information for which local investors have an advantage over foreign investors. 
Financial liberalization and market integration encourage the inflow of institutional investors in emerging markets, and therefore this provides a natural testing ground for the view that differences in the level of institutional investment across stocks account for lead-lag relationships; specifically, for the hypothesis that the prices of stocks with a high level of institutional investment lead those of stocks with low institutional investment. One serious obstacle for this type of work has been the lack of data from embryonic markets on either/both individual stock returns or/and information about institutional ownership. This study fills this gap in the literature by analyzing data from the Trinidad and Tobago Stock Exchange (TTSE). This emerging market is in its embryonic stages of development and has experienced a high level of investment activity over this past decade. In addition, its regulatory, microstructure and information environments are substantially less developed than those of the stock markets in the industrial and larger, emerging economies. For instance, there is a high level of transactions costs and thin trading in this market. (Appendix Table A.1 provides some data on trading activity in TTSE for the period covered by this study, and section 2 provides some background information on the market and regulatory conditions of TTSE.) Much existing work on developed stock markets or advanced emerging markets has explored lead-lag relations in the context of relatively liquid market conditions. Here we are able to explore lead-lag relationships between stocks under relatively illiquid market conditions; conditions that are likely to apply in other smaller and early stage stock markets. (In Appendix Table A.2 we set out some summary information for several other, embryonic stock markets in the Latin America and Caribbean region.) Our main finding is that greater liquidity both increases (ceteris paribus) the lead effect for institutionally favoured stocks and the speed of adjustment or catch-up of lagging, institutionally unfavoured stocks. 
One feature of this study is that it uses both individual stock/firm level data and constructed portfolio information from an emerging market in its embryonic stages of development. The existing literature tends to use only portfolio level data for relatively large emerging markets when exploring lead-lag effects. ${ }^{3}$ Any findings of lead-lag effects in the context of an embryonic market such as TTSE where there is little trading in portfolios could be attributable to a lead-lag relation between some (or even few) of the stocks of the portfolios. This gives rise to the possibility that the results may not be reflective of the true crossautocorrelation between all the stocks in the portfolios. Here we apply our empirical analysis to portfolio information for comparison with the existing literature, but also to returns data at the individual stock level. This provides a robustness test for any identified lead-lag effects between the returns of (individual and portfolios of) stocks with a high institutional investment and those with low institutional investment.

For our empirical tests, and in line with the dominant methodology employed in the literature, we apply a VAR framework to assess lead-lag cross-autocorrelation between 'high' and 'low' institutionally owned stocks in the TTSE. This ensures that any observed lead-lag crossautocorrelation is not a spurious manifestation of the autocorrelation of the low institutional ownership equity returns and the contemporaneous correlations between the low institutional ownership and the high institutional ownership equity returns. Given that other studies (cited above) of the NYSE and some emerging markets find that firm size is correlated with the level of institutional investment, we check that the lead-lag relation is robust across the stocks

\footnotetext{
${ }^{3}$ See, for example, Bohl and Brzeszczyński (2006). Using data on foreign ownership rather than institutional ownership, taken from the EMDB database of emerging stock markets, Bae et al. (2012) also analyse the relationship between lead-lag cross-autocorrelations and the speed of adjustment to new information, but again using portfolio data. Also, the markets in this study are mainly secondary emerging markets (e.g. South Africa, Malaysia, Brazil and Portugal), which are much larger than the TTSE in terms of market capitalization and number of listed firms. They also have liquidity far superior to that of the TTSE.
} 
of firms of different sizes. We also check that the relation is robust across stocks with differing levels of analyst coverage (Brennan et al. 1993). This market characteristic has also been offered as a possible cause of the cross-autocorrelation relationship.

Syriopoulos (2006), analysing lead-lag effects between stock prices from US, Germany and a group of emerging Central European market, finds robust and persistent short-run US stock market effects to Granger cause German and Central Europe stock market reactions. The author attributes these effects to the international leading role of the US stock market that is supported by its market depth (capitalization and turnover). Liquidity effects have also been found by Poshakwale and Theobald (2006) who analyse using stock market data from India the impact of thin trading on lead-lag relationships. We therefore also explore the relationship between institutional ownership and liquidity in the current context, namely for an embryonic and relatively illiquid stock market. We explore both the relative importance of ownership and liquidity effects in accounting directly for lead-lag relationships (across stocks of firms of differing size), and the conditioning influence of liquidity on the ownership effect (through the inclusion of interaction terms). Interestingly we find that the separate, direct effect of institutional ownership (independent of the liquidity effect) holds, but that greater liquidity both increases (ceteris paribus) the lead effect for institutionally favoured stocks and the speed of adjustment or catch-up of lagging, institutionally unfavoured stocks. We view these findings as being strongly supportive of information advantage explanation of the institutional ownership effect in the context of this embryonic equity market.

We organize the remainder of the paper as follows. In Section 2 we briefly describe the microstructure of the TTSE. In Section 3 we present the modelling framework that is employed to test the institutional ownership hypothesis. In Section 4 we describe our data set 
and provide some preliminary descriptive statistics of the relation between institutional ownership and the cross autocorrelation in equity returns. In Section 5 we report our base empirical results on the role of institutional ownership in explaining cross-auto-correlation and some associated robustness analysis, while in Section 6 we explore the relationship between institutional ownership and liquidity effects in the distinctive setting of an embryonic stock market. Finally, we conclude in Section 7.

\section{Brief Overview of the TTSE}

The TTSE was officially established in 1981. Since its establishment, TTSE has undergone several institutional changes to conform with international standards and create modern infrastructures for trading. One major institutional development was the establishment of the Trinidad and Tobago Central Depository (TTCD) in January 1998. The TTCD has functioned as a clearing agent and facilitated efficient and secure operation of book-entry systems. Its establishment was a forerunner to automated, electronic trading on the exchange.

Prior to the automation of trading, the TTSE functioned as a periodic call auction, where securities were traded at discrete time intervals when "calls" were made for securities. Orders were detained at fixed locations (brokerage houses) and then brought to the floor of the TTSE to be executed in a multilateral transaction (batch) at a uniform price when "calls" were made for securities. All bids and offers were made under an open outcry system, which coexisted with a "trading board" that recorded the "calls" and matched the orders of brokers. In order to increase transaction speed and reduce information asymmetries, an automated order-driven system of trading was introduced to the TTSE in March 2005. This facilitated the continuous trading of stocks on the exchange. Trading commences at 9:30 am on the floor of the TTSE (although electronic trading enables brokers to trade also directly 
from their offices). The market, however, enters a pre-open session between 8:00am and 9:30am, on each trading day. During this time, brokers enter orders into the automated system, but these are not immediately matched. The system then calculates the opening trading price for each security, based on the volume of bids and offers made by each broker in the pre-open session. When the market opens, trading occurs in all securities simultaneously. During the course of the trading day, brokers adjust the terms on the remaining orders to either buy or sell shares. The closing price of each security is established by the last price at which it was traded. The introduction of electronic trading has therefore enhanced transparency and transaction speed on TTSE. It has also served to attract an influx of local and regional investors, thereby increasing the market's liquidity and trading frequency.

The TTSE has also undergone several regulatory reforms, since its inception. Chief among these was the establishment of the Trinidad and Tobago Securities and Exchange Commission (TTSEC) in 1995, which is the formal regulatory body for the stock exchange. It supervises all trading activity and seeks to curb illegal and unethical trading practices, such as insider trading and market rigging. Other important legislation was designed to regulate the trading activities of foreign investors. For example, foreign investors were only granted permission to invest in the TTSE in 1997; preventing international investors from holding shares in excess of $30 \%$ of the issued share capital of the listed companies. To acquire additional stocks, these investors require a special licence from the Government of Trinidad and Tobago.

\section{Modelling Framework}

We hypothesize that the returns of stocks with a high level of institutional ownership (institutionally favoured stocks) lead the returns of stocks with a low institutional ownership 
(institutionally unfavoured stocks). ${ }^{4}$ This lead-lag relation would arise when the institutionally favoured stocks reflect market-wide information faster that the institutionally unfavoured stocks. ${ }^{5}$ We assume that institutional investors engage in more informationgathering activities compared to individual investors. This allows them to update their valuations on the stocks more quickly than individual investors.

To examine the above hypothesis, we use a vector autoregression framework, where we evaluate whether returns of $H I$ stocks lead the returns of $L O$ stocks, where $H I$ denotes a firm with high institutional ownership (i.e. are institutionally favoured) and $L O$ denotes the stocks of firm with low institutional ownership (institutionally unfavoured). (The operationalization of the concept of $H I$ and $L O$ stocks in the present study is described in section 4.) This is tested using the following bivariate VAR:

$$
\begin{aligned}
& R_{L O, t}=\alpha_{L O}+\sum_{k=1}^{K} a_{k} R_{L O, t-k}+\sum_{k=1}^{K} b_{k} R_{H I, t-k}+\varepsilon_{t} \\
& R_{H I, t}=\alpha_{H I}+\sum_{k=1}^{K} c_{k} R_{L O, t-k}+\sum_{k=1}^{K} d_{k} R_{H I, t-k}+u_{t}
\end{aligned}
$$

where $R_{L O, t}$ and $R_{H I, t}$ are the returns of stock $L O$ and $H I$, respectively, at time $t . \sum_{k=1}^{K} b_{k}$ in equation (1) and $\sum_{k=1}^{K} c_{k}$ in equation (2) are the sums of the cross-autoregressive coefficients. The number of lags in each equation is selected using the Akaike and Schwartz information criteria. Since the regressors are the same for both equations (1) and (2), the VAR can be efficiently estimated by running ordinary least squares (OLS) on each equation individually.

\footnotetext{
${ }^{4}$ Institutional investors only hold a subset of stocks for which the volume of information and the expected benefits of information collection are large relative to the costs. In addition, these stocks must satisfy legal "prudence" requirements (see Merton, 1987).

${ }_{5}$ Recall that the information gathered by investors pertain to the stocks that they invest in. While some of this information is firm specific, a portion is general in nature and applicable to the pricing of all stocks, that is, market-wide information.
} 
In equation (1), if the lagged values of $R_{H I}$ can predict the contemporaneous value of $R_{L O}$, while controlling for the predictive power of the lagged values of $R_{L O}$, then $R_{H I}$ is said to Granger-cause $R_{L O}{ }^{6}$ We examine whether the sum of the cross-autoregressive coefficients (the coefficients related to the lagged values of $R_{H I}$ ) in equation $(1), \sum_{k=1}^{K} b_{k}$, is statistically different from zero using a Wald test. ${ }^{7}$. If $\sum_{k=1}^{K} b_{k}$ is found to be statistically different from zero, this implies that the lagged $H I$ returns have predictive power for the current $L O$ stock returns, independent to that of the lagged $L O$ returns. This version of the Granger causality test also indicates whether the causal relationship from $H I$ to $L O$ is positive or negative, using the sign attached to the sum of the cross-autoregressive coefficients. Similarly, equation (2) allows us to determine whether the lagged returns of $L O$ are able to forecast the current returns of $H I$, by testing whether the cross-autoregressive coefficient is $\sum_{k=1}^{K} c_{k}$ is statistically different from zero, while controlling for the predictive power of the lagged $R_{H I}$ values.

Next, we test whether the ability of the lagged values of $R_{H I}$ to predict the current value of $R_{L O}$ is better than the ability of the lagged values of $R_{L O}$ to predict the current value of $R_{H I}$. This test of asymmetry in the cross-autocorrelation between the returns of the $H I$ and $L O$ stocks establishes whether $H I$ leads $L O$. To achieve this, we conduct a cross-equation test by evaluating whether the sum of the cross-autoregressive coefficients in equation $(1), \sum_{k=1}^{K} b_{k}$, is

\footnotetext{
${ }^{6}$ We control for the lagged values of $R_{L O}$ to ensure that the cross-autocorrelation between $R_{H I}$ and $R_{L O}$ is not a restatement of $R_{L O}$ 's own return autocorrelation. Under this framework, we are therefore controlling for the possibility that the lagged values of $R_{H I}$ are simply noisy proxies for the lagged values of $R_{L O}$.

${ }^{7}$ This is consistent with Brennan et al. (1993), Sias and Starks (1997), Chordia and Swaminathan (2000), Hou (2007) and Chuang and Lee (2011).
} 
greater than the sum of the cross-autoregressive coefficients in equation (2), $\sum_{k=1}^{K} c_{k}$, where $\sum_{k=1}^{K} b_{k}$ should be statistically different from zero. We use a Wald test to assess the null hypothesis that $\sum_{k=1}^{K} b_{k}=\sum_{k=1}^{K} c_{k}$. If the null is rejected, and the sum of the $b_{k}$ coefficients is greater than the sum of the $c_{k}$ coefficients $\left(\sum_{k=1}^{K} b_{k}>\sum_{k=1}^{K} c_{k}\right)$, we can conclude that the ability of the lagged returns of $H I$ to predict the current $L O$ returns (even after controlling for the own autocorrelation of $L O$ ) is better than the ability of the lagged $L O$ returns to predict the current $H I$ returns. This indicates that the returns of $H I$ lead the returns of $L O$, and $H I$ has a faster speed of adjustment to information than $L O$.

Brennan et al. (1993) show that if the lagged returns of $L O$ predict the current returns of $H I$ with a negative sign, that is, if $\sum_{k=1}^{K} c_{k}$ is negative, while $\sum_{k=1}^{K} b_{k}$ is positive, then the inequality $\sum_{k=1}^{K} b_{k}>\sum_{k=1}^{K} c_{k}$ is met and it can be concluded that $L O$ reacts to information more sluggishly in relation to $H I$. Therefore $H I$ leads $L O$. Chordia and Swaminathan (2000) point out that taking the sign into account makes this version of the Granger Causality test more reliable for assessing lead-lag effects than the conventional Granger Causality test.

\section{Data and Preliminary Statistics}

Our sample consists of each firm listed for trading on the TTSE over the period January 2001 to December 2012. To be included in the sample, a firm must have been listed for trading on the market for the entire sample period. ${ }^{8}$ Thirty firms meet this criterion and are therefore

\footnotetext{
${ }^{8}$ See Table A.3 in the Appendix for the full list of firms.
} 
used in our analysis. For each of these firms, we obtain data on their daily stock returns from the TTSE. We also use data on their daily volume traded and annual market capitalisation from the exchange. Annual data on the percentage of shares held by institutional investors in each firm is compiled using the yearly company reports produced by the Trinidad and Tobago Securities and Exchange Commission (TTSEC). ${ }^{9}$ These institutional investors mainly comprise of financial companies such as banks, insurance companies, pension funds and investment advisors, to name a few. ${ }^{10}$ For the purpose of this study, we measure institutional ownership in each firm using the average of the annual portion of stocks owned by these institutional investors over the sample period. We base our analysis on the mean institutional ownership, as there were no significant changes in the annual level of institutional investment in each firm over the sample period.

Lo and MacKinlay (1990) report that the returns of large firms lead the returns of small firms, that is, the lagged returns of large firms are correlated with the contemporaneous returns of small firms. In our sample, the cross-sectional correlation between the mean firm size and level of institutional ownership is statistically significant at the 5\% level: $\rho=0.373{ }^{11}$ This positive correlation naturally leads to the question of whether firm size effects are subsumed by the institutional ownership effects, or vice versa. We therefore control for any effects which firm size may have on the lead-lag relationship. By controlling for such effects we are able to discern whether the cross-autocorrelation is actually attributed to institutional ownership and not due to the effects of differences in size of the listed firms.

\footnotetext{
${ }^{9}$ Our sample period starts from January 2001 as information on the level of institutional ownership for each firm is only available from this date. Note also that automated trading on the market commenced only in March, 2000.

${ }^{10}$ Note that the finance literature does not consider the government itself to be an institutional investor. It regards the government a separate class of investor. This is noted by Harris (2002), who points out that there are three broad classes of investors, namely individual and institutional investors, and the government. Therefore, the portion of TTSE shares owned by the government is not included as part of our measure of institutional ownership.

${ }^{11} \mathrm{~A}$ number of other studies find that firm size is highly and positively correlated with the level of institutional ownership (for example Badrinath et al., 1995; Sias and Starks, 1997; Næs and Skjeltorp, 2003; Rubin, 2007).
} 
To control for the effects of firm size we form five size based quintiles by ranking the 30 listed firms in our sample according to their average firm size over 2001 to $2012 .^{12}$ Each stock is assigned to one of five quintiles, with six stocks in every quintile. For each one of these quintiles, we test whether the daily returns of the stock with the highest mean level of institutional ownership $(H I)$ leads the daily returns of the stock with the lowest mean level of institutional ownership stock $(L O){ }^{13}$

Table 1 presents descriptive statistics for the $H I$ and $L O$ firms in each size quintile $i=1, \ldots, 5{ }^{14}$ Quintile 1 is the highest size based quintile and 5 is the lowest. Note that in each quintile, the $H I(L O)$ firms represented in this table not only have the highest (lowest) mean institutional ownership, but also have the highest (lowest) institutional ownership in the same quintile for each year in the sample period. For example, the stock RBL has the highest institutional ownership (1) on average and (2) in each year, for quintile 1 over the sample period. There are no cases where stocks are classed as $H I$ / LO in some years but not in other years. This is because the degree of institutional ownership in each firm only changes marginally over the sample period. In which case, the average degree of institutional ownership provides a consistent picture of the level of institutional ownership among stocks and is appropriate for ranking stocks as $H I$ and $L O$.

\footnotetext{
${ }^{12}$ Firm size is measured using the ratio of the firm's market capitalisation to the overall market capitalisation. A higher value of this ratio indicates a larger the firm size. To rank the listed firms according to size, we take the average value of the firm size for each firm over the eight year sample period.

${ }^{13}$ As is noted earlier, we use the mean level of institutional investment, as the annual levels for each stock do not substantially change over the sample period. In fact, we find that there are no cases where some stocks are classed as $H I$ / LO in some years but not in other years. Therefore, those stocks with the highest and lowest institutional ownership in each size quintile remain the same in each year of the sample period.

${ }^{14}$ Note that the various $H I(L O)$ stocks do not belong to the same sector.
} 
Table 1: Summary Statistics for Size-Institutional Ownership Stocks

\begin{tabular}{|c|c|c|c|c|c|c|c|}
\hline \multirow[b]{2}{*}{ Quintile } & \multirow[b]{2}{*}{ Stock } & \multicolumn{2}{|c|}{ Stock Returns } & \multicolumn{2}{|c|}{ Volume } & \multirow[b]{2}{*}{$\begin{array}{r}\text { Mean } \\
\text { Size }\end{array}$} & \multirow[b]{2}{*}{$\begin{array}{c}\text { Mean Institutional } \\
\text { Ownership }\end{array}$} \\
\hline & & Mean\% & Std. Dev. \% & Mean & Std. Dev. & & \\
\hline \multirow[t]{2}{*}{1} & $H I$ & 0.053 & 2.089 & 23578.456 & 115736.900 & 0.158 & 0.833 \\
\hline & $L O$ & -0.029 & 0.742 & 56965.540 & 476053.400 & 0.079 & 0.541 \\
\hline \multirow[t]{2}{*}{2} & $H I$ & 0.177 & 2.688 & 30740.372 & 364153.211 & 0.030 & 0.825 \\
\hline & $L O$ & 0.032 & 2.043 & 9988.220 & 33663.700 & 0.036 & 0.521 \\
\hline \multirow[t]{2}{*}{3} & $H I$ & 0.140 & 1.358 & 2245.797 & 51742.700 & 0.026 & 0.860 \\
\hline & $L O$ & 0.093 & 0.971 & 12421.454 & 346647.315 & 0.018 & 0.412 \\
\hline \multirow[t]{2}{*}{4} & $H I$ & 0.109 & 2.631 & 110402.112 & 466381.450 & 0.009 & 0.770 \\
\hline & $L O$ & 0.023 & 1.711 & 42830.086 & 137024.320 & 0.007 & 0.310 \\
\hline \multirow[t]{2}{*}{5} & $H I$ & 0.119 & 2.061 & 3901.047 & 21216.400 & 0.003 & 0.730 \\
\hline & $L O$ & 0.062 & 0.990 & 8427.645 & 27152.570 & 0.002 & 0.280 \\
\hline
\end{tabular}

Notes: The table presents summary statistics for the highest $(H I)$ and the lowest $(L O)$ institutionally owned stocks in five size based quintiles for the sample period January 2001 to December 2008. These quintiles are formed by ranking all firms listed for trading on the market for the entire sample period, where quintile 1 refers to the highest size quintile while 5 is the lowest. Size refers to the average annual size of the $H I$ and $L O$ stocks in each quintile over the sample period. We compute size by firstly finding the average of each stock's market capitalisation expressed as a proportion of the total market capitalisation over the sample period. Institutional ownership denotes the mean of the annual values of the proportion of stocks held by institutional investors over our sample period.

Table 1 shows that for all the quintiles, the overall mean and standard deviation of the daily returns for the $H I$ stocks are higher than those of the $L O$ stocks. The table also reports the mean size and institutional ownership for the $H I$ and $L O$ stocks in each quintile over our sample period. We also find in all quintiles that the mean institutional ownership increases with firm size, implying that institutional investors favour large capitalised stocks over small capitalised stocks. This pattern is also found by Chuang and Lee (2011). This provides an opportunity to test whether institutional ownership has an independent influence on the crossautocorrelation patterns. Such a result may suggest that some institutional traders invest in smaller stocks for the purpose of portfolio diversification or increasing profits, despite the 
possibility of incurring high information set-up costs associated with these stocks. If institutional ownership does indeed have an independent effect, then the returns on the $H I$ stock should lead the returns on the $L O$ stock in quintile 2. If, on the other hand, institutional ownership is simply a proxy of firm size, then the $L O$ stock returns should lead the $H I$ stock returns in quintile 2.

Further, the table shows that the mean volume of $H I$ and $L O$ stocks traded does not increase with firm size. We also find that the cross-sectional correlation between the average volume traded and the average firm size of the thirty stocks in our sample is statistically insignificant: $\rho=0.164 .^{15}$ In this regard, volume does not proxy for firm size, which implies that any relation uncovered between liquidity and the lead-lag relation is independent of firm size. We also find that the volume traded does not proxy for the level of institutional ownership. The table shows that the mean and the standard deviation of the volume of $H I$ stocks traded are lower than those of the $L O$ stocks in quintiles (1 and 3). Moreover, the cross-sectional correlation between these variables, which is computed using the thirty stocks in our sample, is not statistically significant: $\rho=0.110$. Such a finding is in contrast to Sias and Starks (1997), who point out that high institutionally owned stocks should be more liquid, as there are lower transaction costs associated with such stocks. ${ }^{16}$ This, however, may not hold in the case of an emerging market such as the TTSE, as microstructures are different. Specifically, there are more severe thin-trading and higher transaction costs associated with the stocks in this market, in comparison to developed markets. Therefore, it may be possible that some stocks with a high institutional ownership may not trade very often, and would therefore have a lower liquidity.

\footnotetext{
${ }^{15}$ This is in contrast to Chordia and Swaminathan (2000), who find that volumes traded are highly and positively correlated.

${ }^{16}$ Sias and Starks (1997) conducted their analysis on institutional investment and return autocorrelation / crossautocorrelation using stocks from the NYSE.
} 
Table 2: Contemporaneous Correlation between $H I$ and $L O$ stocks.

\begin{tabular}{|c|c|c|c|c|c|c|c|c|c|c|}
\hline & $R_{L O 1}$ & $R_{H I 1}$ & $R_{L O 2}$ & $R_{H I 2}$ & $R_{L O 3}$ & $R_{H I 3}$ & $R_{L O 4}$ & $R_{H I 4}$ & $R_{L O 5}$ & $R_{H I 5}$ \\
\hline$R_{L O 1}$ & 1 & & & & & & & & & \\
\hline$R_{H I 1}$ & $0.061 * *$ & 1 & & & & & & & & \\
\hline$R_{\mathrm{LO} 2}$ & $0.188 * *$ & $0.152 * *$ & 1 & & & & & & & \\
\hline$R_{H I 2}$ & $0.083 * *$ & $0.153 * *$ & $0.230 * *$ & 1 & & & & & & \\
\hline$R_{L O 3}$ & $0.120 * *$ & 0.022 & $0.141 * *$ & $0.075^{* *}$ & 1 & & & & & \\
\hline$R_{H I 3}$ & $0.165 * *$ & $-0.262 * *$ & $0.049 * *$ & -0.013 & $0.086^{* *}$ & 1 & & & & \\
\hline$R_{L O 4}$ & $-0.124 * *$ & $0.206^{* *}$ & $-0.193 * *$ & -0.011 & $-0.150 * *$ & $-0.210 * *$ & 1 & & & \\
\hline$R_{H I 4}$ & 0.017 & $0.053 * *$ & -0.020 & -0.008 & 0.025 & 0.013 & $0.128 * *$ & 1 & & \\
\hline$R_{L O 5}$ & $0.045^{* *}$ & $0.240 * *$ & $0.119 * *$ & $0.086 * *$ & 0.025 & $-0.116^{* *}$ & $0.056^{* *}$ & $0.054 * *$ & 1 & \\
\hline$R_{H I 5}$ & $0.166^{* *}$ & $-0.122 * *$ & $0.205^{* *}$ & $0.055^{* *}$ & $0.133 * *$ & $0.164 * *$ & $-0.266^{* *}$ & 0.001 & $0.094 * *$ & 1 \\
\hline
\end{tabular}

Note: $* *$ and * refers to statistical significance at the $5 \%$ and $10 \%$ level. The table shows the correlation coefficients for the returns of the low and high institutionally owned stocks, $R_{L O i}$ and $R_{H I i}$ respectively, in each size based quintile $i$ respectively. $i=$ 1 refers to the largest size quintile while $i=5$ is the smallest size quintile.

Table 3: Own Autocorrelation Coefficients

\begin{tabular}{|c|c|c|c|c|c|c|}
\hline Quintile & Stock & $\rho_{I}$ & $\rho_{2}$ & $\rho_{3}$ & $\rho_{4}$ & $\rho_{5}$ \\
\hline \multirow{2}{*}{1} & $R_{H I}$ & -0.015 & 0.023 & 0.031 & 0.011 & 0.015 \\
\hline & $R_{L O}$ & $0.141 * *$ & $0.119 * *$ & $0.048 * *$ & $0.034 *$ & 0.017 \\
\hline \multirow{2}{*}{2} & $R_{H I}$ & 0.032 & 0.028 & 0.026 & 0.003 & 0.011 \\
\hline & $R_{L O}$ & $0.044 * *$ & $0.167 * *$ & $0.060 * *$ & 0.031 & $0.038 *$ \\
\hline \multirow{2}{*}{3} & $R_{H I}$ & $0.159 * *$ & $0.093 * *$ & 0.027 & -0.021 & 0.004 \\
\hline & $R_{L O}$ & $0.318 * *$ & $0.151 * *$ & $0.066 * *$ & $0.034 *$ & $0.053 * *$ \\
\hline \multirow{2}{*}{4} & $R_{H I}$ & $0.117^{* *}$ & $0.241 * *$ & 0.006 & 0.012 & 0.006 \\
\hline & $R_{L O}$ & $0.128 * *$ & $0.129 * *$ & $0.081 * *$ & $0.060 * *$ & 0.027 \\
\hline \multirow{2}{*}{5} & $R_{H I}$ & $0.147 * *$ & 0.003 & 0.001 & -0.004 & 0.005 \\
\hline & $R_{L O}$ & $-0.054 * *$ & $0.127 * *$ & $-0.159 * *$ & $0.160 * *$ & $0.081 * *$ \\
\hline
\end{tabular}

Notes: $* *$ and $*$ refers to statistical significance at the $5 \%$ and $10 \%$ level. The table reports the first- through fifth-order autocorrelation coefficients for the returns of the $H I$ and $L O$ stocks $\left(R_{H I}\right.$ and $R_{L O}$ respectively). 
Table 2 depicts the contemporaneous correlation between the returns of the $H I$ and $L O$ stocks in each size quintile, while Table 3 reports, for each quintile, the first- through fifth-order autocorrelation coefficients for the returns of the $H I$ and $L O$ stocks. We find that the majority of the autocorrelation coefficients on the $H I$ stocks are not statistically significant, with the $H I$ stock in the largest quintile having no significant coefficients. By contrast, the bulk of the statistically significant autocorrelation coefficients for the $L O$ stocks are positive. The low autocorrelation in the $H I$ stocks is consistent with the hypothesis that the high institutionally owned stocks adjust quickly to common information. In addition, the positive autocorrelation in $L O$ stocks suggests that these stocks adjust slowly to information.

Table 4: Cross-Correlation Coefficients

\begin{tabular}{|c|c|c|c|c|c|}
\hline & $\begin{array}{l}\text { Quintile } \\
1\end{array}$ & $\begin{array}{l}\text { Quintile } \\
2\end{array}$ & $\begin{array}{l}\text { Quintile } \\
\mathbf{3} \\
\end{array}$ & $\begin{array}{l}\text { Quintile } \\
4 \\
\end{array}$ & $\begin{array}{l}\text { Quintile } \\
5\end{array}$ \\
\hline$\rho\left(R_{L O, t} R_{H I, t}\right)$ & $0.061 * *$ & $0.230 * *$ & $0.086 * *$ & $0.128 * *$ & $0.094^{* *}$ \\
\hline$\rho\left(R_{L O, t,} R_{H I, t-1}\right)$ & $0.050 * *$ & $0.231 * *$ & $0.264 * *$ & $-0.046 * *$ & 0.018 \\
\hline$\rho\left(R_{H I, t, t} R_{L O, t-1}\right)$ & $0.089 * *$ & $-0.069 * *$ & $0.053 * *$ & $-0.055^{* *}$ & 0.017 \\
\hline$\rho\left(R_{L O, t,} R_{H I, t-2}\right)$ & $0.127 * *$ & $0.077 * *$ & $0.179 * *$ & $0.061 * *$ & $0.041 * *$ \\
\hline$\rho\left(R_{H I, t,} R_{L O, t-2}\right)$ & 0.027 & 0.013 & 0.016 & 0.011 & 0.007 \\
\hline$\rho\left(R_{L O, t,} R_{H I, t-3}\right)$ & -0.017 & $0.035 *$ & -0.011 & $0.059 * *$ & $0.150 * *$ \\
\hline$\rho\left(R_{H I, t,} R_{L O, t-3}\right)$ & 0.009 & 0.011 & 0.019 & $-0.038 *$ & -0.012 \\
\hline$\rho\left(R_{L O, t,} R_{H I, t-4}\right)$ & $0.065 * *$ & 0.012 & $0.063 * *$ & $0.091 * *$ & -0.014 \\
\hline$\rho\left(R_{H I, t, t} R_{L O, t-4}\right)$ & 0.001 & 0.004 & -0.012 & 0.016 & $-0.053 * *$ \\
\hline$\rho\left(R_{L O, t,} R_{H I, t-5}\right)$ & $0.081 * *$ & $0.058 * *$ & 0.028 & $0.083 * *$ & 0.007 \\
\hline$\rho\left(R_{H I, t,} R_{L O, t-5}\right)$ & -0.004 & -0.011 & 0.016 & -0.007 & 0.019 \\
\hline
\end{tabular}

Note: $* *$ and $*$ refers to statistical significance at the $5 \%$ and $10 \%$ level. The table shows the cross-correlation coefficients for $R_{L O}$ and $R_{H I}$ in each size based quintile. Specifically, $\rho\left(R_{L O, t,} R_{H, t-i-i}\right)$ refers to the cross-correlation between $R_{L O, t}$ and $R_{H I, t-i}$ while $\rho\left(R_{H I, t,} R_{L O, t-i}\right)$ depicts the cross-correlation between $R_{H I, t,}$ and $R_{L O, t-i} . i=1, \ldots, 5$. 
Finally, Table 4 provides some initial evidence of lead-lag cross-autocorrelation between the $H I$ and $L O$ stocks. Specifically, it reports the contemporaneous correlations between both types of stocks for each quintile. It also provides the first- through fifth-order crossautocorrelations coefficients between the lagged returns on the $H I$ stocks and the current returns on the $L O$ stocks in each quintile. We find that the contemporaneous correlation between the $H I$ and $L O$ stocks in all quintiles is positive and statistically significant. In addition, for each quintile, the extent to which the lagged $H I$ returns are correlated with the current $L O$ returns, is generally greater than the extent to which the lagged $L O$ returns are correlated with the current $H I$ returns. This asymmetry in the cross-autocorrelation provides some preliminary evidence consistent with the hypothesis that the lagged returns of the high institutionally owned stocks predict the current returns of the low institutionally owned stocks better than vice versa. However, this cross-autocorrelation pattern could be a manifestation of the high autocorrelation in the returns of the $L O$ firms (observed in Table 3) coupled with high contemporaneous correlation between the between the $H I$ and $L O$ firms. ${ }^{17}$ The lagged returns of the $H I$ firms may be noisy proxies for the lagged returns of the $L O$ firms, and once the lagged returns of the $L O$ firms are controlled for, this cross-correlation pattern could disappear. It is essential therefore to control for the lagged $L O$ returns in the VAR analysis.

\section{Empirical Results}

Table 5 presents the results of the bivariate VAR analysis. The VARs are estimated using the returns of the highest $(H I)$ and lowest $(L O)$ institutionally favoured stocks in five size quintiles: $\left(\mathrm{LO}_{1}, \mathrm{HI}_{1}\right),\left(\mathrm{LO}_{2}, \mathrm{HI}_{2}\right),\left(\mathrm{LO}_{3}, \mathrm{HI}_{3}\right),\left(\mathrm{LO}_{4}, \mathrm{HI}_{4}\right),\left(\mathrm{LO}_{5}, \mathrm{HI}_{5}\right)$. The suffixes $1 \ldots 5$ denote the size quintiles, with 1 representing the highest quintile and 5 the lowest. The number of lags in each VAR is selected on the basis of the Akaike Information Criteria (AIC) and the

\footnotetext{
${ }^{17}$ This is also pointed out by Boudoukh et al. (1994), Hameed (1997) and Hou (2007).
} 
Schwarz Information Criteria (SIC). Where these two criteria indicate different lag lengths, the lesser lag length is chosen for the sake of parsimony. The sum of the coefficients reported is the sum of the cross-autoregressive slope coefficients, namely $\sum_{k=1}^{K} b_{k}$ from equation (1) or $\sum_{k=1}^{K} c_{k}$ from equation (2), as per the dependent variable.

There is strong evidence that the lagged returns of the highest institutionally owned stocks $(H I)$ predict the contemporaneous returns on the stocks with the lowest institutional ownership $(L O)$. For each size quintile, the Wald (a) statistics are statistically significant, implying that the sum of the slope coefficients corresponding to the lagged returns of the $H I$ stocks, $\sum_{k=1}^{K} b_{k}$, is typically different from zero. In addition, $\sum_{k=1}^{K} b_{k}$ is positive in each quintile, which implies that the cross-autocorrelation relationship between stock $H I$ and $L O$ is positive. There is, however, little evidence that the lagged returns on $L O$ stocks reliably forecast the current returns on $H I$ stocks. We find that for four size quintiles (2, 3, 4 and 5), the sum of the coefficients on the lagged returns of the $L O$ stocks are not statistically different from zero, as implied by the insignificant Wald (a) statistics. For these four quintiles, therefore, the lagged returns of the $L O$ stocks are unable to predict the current returns of the $H I$ stocks.

Furthermore, the results also show that for each size quintile, the ability of the lagged $H I$ stock returns to predict the current $L O$ stock returns exceeds the ability of the lagged $L O$ stock returns to predict current $H I$ stock returns. For each of the five pairs of regressions, the sum of the $b_{k}$ coefficients on the lagged $H I$ stocks are found to exceed the sum of the $c_{k}$, coefficients on the lagged $L O$ stocks $\left(\sum_{k=1}^{K} b_{k}>\sum_{k=1}^{K} c_{k}\right)$ while the Wald (b) test statistic rejects the null hypothesis that $\sum_{k=1}^{K} b_{k}=\sum_{k=1}^{K} c_{k}$. These results confirm our hypothesis that the returns of the $H I$ stocks lead the returns of the $L O$ stocks. 
Table 5: Vector Autoregressions for the Size-Institutional Ownership Stocks

\begin{tabular}{|c|c|c|c|c|c|c|}
\hline Quintile & $\begin{array}{l}\text { Dependent } \\
\text { Variable }\end{array}$ & $\begin{array}{l}\text { Lag } \\
\text { Length }\end{array}$ & $\begin{array}{l}\text { Sum of } \\
\text { Coefficients }\end{array}$ & Wald (a) & Wald (b) & $\begin{array}{l}H I \text { leads } \\
L O\end{array}$ \\
\hline \multirow{2}{*}{1} & $R_{L O 1, t}$ & 3 & 0.293 & & \multirow{2}{*}{$6.915 * *$} & \multirow{2}{*}{ Yes } \\
\hline & $R_{H I I, t}$ & 3 & 0.031 & $7.962 * *$ & & \\
\hline \multirow{2}{*}{2} & $R_{L O 2, t}$ & 3 & 0.663 & $76.111 * *$ & \multirow{2}{*}{$73.332 * *$} & \multirow{2}{*}{ Yes } \\
\hline & $R_{H I 2, t}$ & 3 & -0.035 & 1.715 & & \\
\hline \multirow{2}{*}{3} & $R_{L O 3, t}$ & 3 & 0.211 & $17.771 * *$ & \multirow{2}{*}{$17.482 * *$} & \multirow{2}{*}{ Yes } \\
\hline & $R_{H I 3, t}$ & 3 & -0.070 & 2.461 & & \\
\hline \multirow{2}{*}{4} & $R_{L O 4, t}$ & 6 & 0.288 & $7.085 * *$ & \multirow{2}{*}{$8.157 * *$} & \multirow{2}{*}{ Yes } \\
\hline & $R_{H I 4, t}$ & 6 & -0.032 & 1.201 & & \\
\hline \multirow{2}{*}{5} & $R_{L O 5, t}$ & 7 & 0.352 & $7.203 * *$ & \multirow{2}{*}{$6.975 * *$} & \multirow{2}{*}{ Yes } \\
\hline & $R_{H I 5, t}$ & 7 & 0.017 & 0.046 & & \\
\hline
\end{tabular}

Note: ** and * refers to statistical significance at the 5\% and $10 \%$ level. The endogenous variables, $R_{L O i, t}$ and $R_{H I i, t}$, are the daily returns on the stocks with the lowest and highest institutional ownership respectively, within each size based quintile $i . i=1$ refers to the largest size quintile while $i=5$ is the smallest size quintile. The lag length in each regression is selected on the basis of the Akaike (1974) and Schwartz (1978) information criteria. The sum of the coefficients reported is the sum of the cross-autoregressive coefficients, namely $\sum_{k=1}^{K} b_{k}$ from equation (1) or $\sum_{k=1}^{K} c_{k}$ from equation (2), as per the dependent variable. For example, when $R_{L O i, t}$ is the dependent variable, the sum of the coefficients provided is $\sum_{k=1}^{K} b_{k}$, which indicates the extent that lagged $R_{H I i, t}$ can forecast current $R_{L O i, t}$. Wald (a) is the Wald statistic obtained from a joint test of the null hypothesis that $\sum_{k=1}^{K} b_{k}=0$ and $\sum_{k=1}^{K} c_{k}=0$. Wald (b) is the Wald statistic corresponding to the cross-equation null hypothesis that $\sum_{k=1}^{K} b_{k}=\sum_{k=1}^{K} c_{k}$. If the ability of the lagged $R_{H I i, t}$ to predict the current $R_{L O I, t}$ is better than the ability of the lagged $R_{L O i, t}$ to predict the current $R_{H I i, t}$, then the following criteria must be fulfilled: (1) Wald (a) should be statistically significant, rejecting the null $\sum_{k=1}^{K} b_{k}=0$, (2) the Wald (b) test should reject the null $\sum_{k=1}^{K} b_{k}=\sum_{k=1}^{K} c_{k}$, and (3) $\sum_{k=1}^{K} b_{k}>\sum_{k=1}^{K} c_{k}$. This would imply that the $R_{H I i, t}$ adjusts to new information faster than $R_{L O i, t}$.

As an initial check on the reliability of our base results, we investigated the crossautocorrelation between an equally weighted market portfolio $(M P)$ and first $H I$ stocks and then $L O$ stocks. These estimation results are set out in Appendix tables A.4 and A.5 respectively. Overall, these results indicate that the stocks returns of firms with high institutional ownership lead the market portfolio, while the returns of $M P$ lead the returns of $L O$. The above results are consistent with the faster adjustment of institutionally favoured stocks than the market portfolio (which is a mixture of $H I$ and $L O$ stocks) to new information, 
but with the market portfolio adjusting to current information more quickly than the low institutional ownership stocks. By the time that low institutionally owned stocks reflect new information, this information will have already been incorporated in the historical returns of the market portfolio, giving rise to a lead-lag effect from the market portfolio to the low institutionally owned stocks.

Brennan et al. (1993) document that the level of analyst coverage received by firms also affects the speed of stock price adjustment to information. The higher the number of analysts covering a firm, the greater the information generated about that firm. This increases the number of informed investors, which in turn causes its share price to reflect more information rapidly. As such, the prices of stocks with higher analyst coverage impound information faster than those stocks with a lower coverage. This gives rise to a lead-lag effect where the firms with high analyst coverage lead the returns of firms with low analyst coverage.

The analyst coverage of a particular firm is defined here as the number of analysts making annual earnings forecasts for that firm in December of the previous year. In our sample, the crosssectional correlation between analyst coverage and institutional investors is statistically significant at the 5\% level: $\rho=0.389$. This positive correlation naturally leads to the question of whether the analyst coverage effects are captured by the institutional ownership effects, or vice versa. We therefore repeat the above cross-autocorrelation analysis, while controlling for any effects which the level of analyst coverage received by the listed firms may have on the lead-lag relationship.

We control for the effects of analyst coverage similar to the manner in which we previously controlled for firm size. Five analyst coverage quintiles are formed, by ranking all listed firms 
according to the average analyst coverage received by each of them (measured by the number of analysts following each firm/stock over the period 2001 to 2012$).{ }^{18}$ In each quintile, we test whether the returns of the highest institutional ownership stock leads the returns of the lowest institutionally owned stock. This testing is also conducted in a bivariate VAR framework, and the results are presented in Table 6.

Table 6: Vector Autoregressions for the Analyst-Institutional Ownership Stocks

\begin{tabular}{|c|c|c|c|c|c|c|}
\hline Quintile & $\begin{array}{l}\text { Dependent } \\
\text { Variable }\end{array}$ & $\begin{array}{l}\text { Lag } \\
\text { Length }\end{array}$ & $\begin{array}{l}\text { Sum of } \\
\text { Coefficients }\end{array}$ & Wald (a) & Wald (b) & $\begin{array}{l}\text { HI leads } \\
M P\end{array}$ \\
\hline \multirow{2}{*}{1} & $R_{L O l, t}$ & 3 & 0.182 & $11.198 * *$ & \multirow{2}{*}{$7.013 * *$} & \multirow{2}{*}{ Yes } \\
\hline & $R_{H I l, t}$ & 3 & 0.022 & 0.738 & & \\
\hline \multirow{2}{*}{2} & $R_{L O 2, t}$ & 4 & 0.176 & $4.377 * *$ & \multirow{2}{*}{$5.004 * *$} & \multirow{2}{*}{ Yes } \\
\hline & $R_{H I 2, t}$ & 4 & -0.015 & 1.021 & & \\
\hline \multirow{2}{*}{3} & $R_{L O 3, t}$ & 4 & 0.066 & 1.265 & \multirow{2}{*}{0.438} & \multirow{2}{*}{ No } \\
\hline & $R_{H I 3, t}$ & 4 & 0.024 & 0.985 & & \\
\hline \multirow{2}{*}{4} & $R_{L O 4, t}$ & 5 & 0.176 & $12.068 * *$ & \multirow{2}{*}{$7.674 * *$} & \multirow{2}{*}{ Yes } \\
\hline & $R_{H I 4, t}$ & 5 & 0.068 & 1.226 & & \\
\hline \multirow{2}{*}{5} & $R_{L O 5, t}$ & 3 & 0.227 & $20.785 * *$ & \multirow{2}{*}{$6.137 * *$} & \multirow{2}{*}{ Yes } \\
\hline & $R_{H I 5, t}$ & 3 & 0.048 & 0.854 & & \\
\hline
\end{tabular}

Note: $* *$ and $*$ refers to statistical significance at the $5 \%$ and $10 \%$ level. See also notes for Table 5.

We find that the results are generally consistent with those in Table 5. Table 6 confirms that there is a lead-lag cross-autocorrelation from the $H I$ to the $L O$ stocks. Specifically, the extent to which the informational content of the historical returns of the $H I$ stocks is relevant to the current pricing of the $L O$ stocks is greater than vice versa.

\footnotetext{
${ }^{18}$ To rank the listed firms, we take the average of the number of analysts for each firm over the eight year sample period. This information is obtained from the research department of the TTSEC. This measure of analyst coverage is also used in Brennan et al. (1993) and Chuang and Lee (2011).
} 


\section{Extending the Analysis}

\subsection{Liquidity Effects}

We extend the analysis from the previous section by exploring whether the institutional ownership role in the identified lead-lag effect is proxing for or fashioned by liquidity effects. ${ }^{19}$. For this purpose, we estimate equation (3), which allows both for the possibility of a direct effect of liquidity on the lead-lag relation from the $H I$ to the $L O$ stocks in each sizebased quintile and for a conditioning or interaction effect via the level of institutional ownership :

$$
\begin{aligned}
R_{L O i, t}= & \alpha_{L O i}+\sum_{k=1}^{K} a_{1, k} R_{L O, t-k}+\sum_{k=1}^{K} a_{2, k} L i q_{L O, t-k}+\sum_{K=1}^{K} b_{1, \mathrm{k}} R_{H I, t-k}+\sum_{K=1}^{K} b_{2, k} L i q_{H I, t-k}+ \\
& \sum_{k=1}^{K} b_{3, k}\left(R_{H I} * L i q_{H I}\right)_{t-k}+\sum_{k=1}^{K} b_{4, k}\left(R_{H I} * L i q_{L O}\right)_{t-k}+\varepsilon_{t}
\end{aligned}
$$

where $R_{H I, t}$ and $R_{L O, t}$ denote the returns of the stocks $H I$ and $L O$ respectively at time $t . L i q_{L O, t}$ and $\operatorname{Liq}_{H, t}$ denote the liquidity of low institutional ownership and high institutional ownership stocks respectively, on day $t$. We measure liquidity using the volume of $L O$ and $H I$ stocks traded on each day. ${ }^{20}$ As a robustness check we have also used stock turnover as a measure of liquidity. Our conclusions are not affected by which measure we use (see Table A.6 in the Appendix).

The results of this estimation are presented in Table 7. Panels A to E of this table provide the results for each size- based quintile, with Panel A reporting the results for the largest quintile (dependent variable $-R_{L O, 1}$ ) and Panel E reporting the results for the smallest quintile

\footnotetext{
${ }^{19}$ As pointed earlier, Chordia and Swaminathan (2000) argue that variation in liquidity across stocks is a possible reason for lead-lag effects.

${ }^{20}$ Jones et al. (1994) and Datar et al. (1998) argue that volume traded and volume related measures of liquidity are highly correlated with the number of trades (trading frequency), which is the most direct measure of liquidity. To this end, we measure liquidity using the daily volume of stocks traded.

${ }^{21}$ We control for liquidity, specifically the volume traded, since there is likely to be a causal relationship between volume traded and stock returns. Evidence of this is given in a number of studies including Jennings, Starks and Fellingham (1981), Gallant, Rossi and Tauchen (1992), Heimstra and Jones (1994), Blume, Easley and O’Hara (1994) and Brennan, Chordia and Subramanyam (1998).
} 
(dependent variable $-R_{L O, 5}$ ). We present the sum of the coefficients of each explanatory variable in the regression in column (2). Column (3) gives the Wald test statistics for the null hypothesis that the sums of the coefficients of the explanatory variables are statistically different significantly different from zero. The joint test is a Wald test of the null hypothesis that the coefficients of all explanatory variables are jointly significant. The direct liquidity effect is captured by the sum of the $a_{2}$ or $b_{2}$ coefficients in eq. 3 , and the conditioning effect from the sum of the $b_{3}$ or $b_{4}$ coefficients.

Table 7: Impact of Liquidity on Cross-autocorrelation

\begin{tabular}{|c|c|c|}
\hline Equation (1) & Sum of Coefficients & Wald Test \\
\hline \multicolumn{3}{|c|}{ Panel A: (Quintile 1) Dependent Variable - $\mathbf{R}_{L O 1, t}$} \\
\hline$R_{L O I, t}$ & 0.234 & $59.805 * *$ \\
\hline$R_{H I 1, t-k}$ & 0.292 & $8.423 * *$ \\
\hline$L i q_{H I I, t-k}$ & $6.13 \mathrm{E}-09$ & 1.034 \\
\hline $\operatorname{Liq}_{L O 1, t-k}$ & 3.13E-09 & 1.201 \\
\hline$R_{H I I, t-k} * \operatorname{Liq}_{H I I, t-k}$ & $1.12 \mathrm{E}-06$ & $10.322 * *$ \\
\hline$R_{H I I, t-k} * \operatorname{Liq}_{L O I, t-k}$ & $-1.70 \mathrm{E}-06$ & $34.080 * *$ \\
\hline \multicolumn{3}{|c|}{ AIC $/$ SIC $=3$ Joint test $=208.776 * *$ Adj- $\mathrm{R}^{2}=0.073$} \\
\hline \multicolumn{3}{|c|}{ Panel B: (Quintile 2) Dependent Variable $-\mathbf{R}_{\mathrm{LO2,t}}$} \\
\hline$R_{L O 2, t}$ & 0.188 & $31.166^{* *}$ \\
\hline$R_{H I 2, t-k}$ & 0.626 & $94.243 * *$ \\
\hline$L i q_{H I 2, t-k}$ & $-1.29 \mathrm{E}-08$ & 0.189 \\
\hline $\operatorname{Liq}_{L O 2, t-k}$ & 7.54E-09 & $9.371 * *$ \\
\hline$R_{H I 2, t-k} * L_{i q} q_{I I, t-k}$ & $4.86 \mathrm{E}-06$ & $12.329 * *$ \\
\hline$R_{H I 2, t-k} * L_{L i} q_{L O 2, t-k}$ & $-5.58 \mathrm{E}-06$ & $16.248 * *$ \\
\hline \multicolumn{3}{|c|}{ AIC/SIC $=3$ Joint test: Wald $=430.007 * *$ Adj-R $R^{2}=0.145$} \\
\hline \multicolumn{3}{|c|}{ Panel C: (Quintile 3) Dependent Variable $-\boldsymbol{R}_{L O 3, t}$} \\
\hline$R_{L O 3, t}$ & 0.176 & $28.160 * *$ \\
\hline$R_{H I 3, t-k}$ & 0.317 & $10.429 * *$ \\
\hline$L i q_{H I 3, t-k}$ & $2.78 \mathrm{E}-09$ & 0.604 \\
\hline $\operatorname{Liq}_{L O 3, t-k}$ & $1.01 \mathrm{E}-08$ & $3.002 *$ \\
\hline$R_{H I 3, t-k} * L i q_{H I 3, t-k}$ & $1.05 \mathrm{E}-06$ & $6.306^{* *}$ \\
\hline$R_{H I 3, t-k} * \operatorname{Liq}_{L O 3, t-k}$ & $-9.26 \mathrm{E}-07$ & $5.059 * *$ \\
\hline \multicolumn{3}{|c|}{ AIC/SIC $=3$ Joint test: Wald $=244.611 * * A d j-R^{2}=0.185$} \\
\hline \multicolumn{3}{|c|}{ Panel D: (Quintile 4) Dependent Variable - $\mathbf{R}_{\mathrm{LO4,t}}$} \\
\hline$R_{L O 4, t}$ & -0.459 & $78.566 * *$ \\
\hline$R_{H I 4, t-k}$ & 0.520 & $7.289 * *$ \\
\hline$L i q_{H I 4, t-k}$ & $3.53 \mathrm{E}-09$ & 0.273 \\
\hline
\end{tabular}




\begin{tabular}{|c|c|c|}
\hline $\operatorname{Liq}_{L O 4, t-k}$ & $4.02 \mathrm{E}-08$ & $4.731 * *$ \\
\hline$R_{H I 4, t-k} * L_{i q} q_{H 4, t-k}$ & $1.05 \mathrm{E}-05$ & $25.126 * *$ \\
\hline$R_{H I 4, t-k} * L_{i q} q_{L 4, t-k}$ & $-3.04 \mathrm{E}-05$ & $23.356 * *$ \\
\hline \multicolumn{3}{|c|}{ AIC/SIC $=4$ Joint test: Wald $=565.589 * *$ Adj-R ${ }^{2}=0.221$} \\
\hline \multicolumn{3}{|c|}{ Panel E: (Quintile 5) Dependent Variable - $\mathbf{R}_{\mathrm{LO5,t}}$} \\
\hline$R_{L O 5, t}$ & 0.280 & $77.031 * *$ \\
\hline$R_{H I 5, t-k}$ & 0.195 & $16.744 * *$ \\
\hline$L i q_{H I 5, t-k}$ & $-1.85 \mathrm{E}-09$ & 0.422 \\
\hline $\operatorname{Liq}_{L O 5, t-k}$ & $7.60 \mathrm{E}-08$ & $4.064 * *$ \\
\hline$R_{H I 5, t-k} * L i q_{H I 5, t-k}$ & 4.51E-07 & $7.127 * *$ \\
\hline$R_{H I 5, t-k} * \operatorname{Liq}_{L O 5, t-k}$ & $-1.08 \mathrm{E}-06$ & $39.757 * *$ \\
\hline \multicolumn{3}{|c|}{ AIC/SIC $=3$ Joint test: Wald $=266.012 * *$ Adj- $R^{2}=0.416$} \\
\hline
\end{tabular}

Note: $* *$ and * refers to statistical significance at 5\% and $10 \%$. The lag length in each regression is selected on the basis of the Akaike (1974) and Schwartz (1978) information criteria. The Wald test reports chi-square statistics for the null hypothesis that the sums of the coefficients of each explanatory variable are statistically significant.

It is clear from Table 6 that the liquidity of the $H I$ stocks influences the extent to which the $H I$ stocks lead the $L O$ stocks. We find that the sum of the coefficients on the lagged interaction term $R_{H I} * L i q_{H I}$ is positive in each quintile, and strongly significant in all five quintiles. The results are consistent with a hypothesis that the lead-lag relation from the returns of the $H I$ stocks to the returns of the $L O$ stocks is stronger when the $H I$ stocks are more liquid. This can be attributed to the $H I$ stocks responding to contemporaneous marketwide information more rapidly when their liquidity increases.

The results in Table 6 further suggest that the ability of the $H I$ returns to lead the $L O$ returns diminishes with an increase in the $L O$ stock liquidity. In all quintiles, we find that the sum of the coefficients on the lagged interaction term $R_{H I} * L i q_{L O}$ is negative and statistically different from zero. Such findings arise as higher liquidity in the $L O$ stocks reduces the delay to which new market-wide information is reflected in the prices of these stocks. Although information is impounded in the $H I$ stocks first, causing $H I$ to lead $L O$, a faster adjustment of the $L O$ stocks to new information lowers the extent to which the informational content of the lagged $H I$ stocks returns are useful for the future pricing of the $L O$ stocks. This could have 
implications for arbitrage activity in the equity market. Arbitrageurs, who are aware of the lead-lag relation from $H I$ to $L O$ stocks, may attempt to profit by using the historical prices of the $H I$ stocks to predict the future prices of the $L O$ stocks.

\subsection{Portfolio Approach}

We also assess the validity of our results by adopting a portfolio approach. Specifically, we examine whether the returns of portfolios consisting of $H I$ stocks lead the returns of portfolios consisting of $L O$ stocks. The portfolios are constructed as follows. Three equal size based terciles are formed by ranking the thirty stocks in our sample according to their average market capitalisation for the sample period. These terciles are then divided into two equal portfolios, based on their average level of institutional ownership for the sample period. For each of these terciles, we test whether the returns of the portfolio with the higher level of institutional ownership $\left(R P_{H I}\right)$ leads the portfolio with the lower level of institutional ownership $\left(R P_{L O}\right) .^{22}$ The sum of the coefficients reported is the sum of the crossautoregressive coefficients. For example, when $R P_{L O i, t}$ is the dependent variable, the sum of the coefficients indicates the extent that lagged $R P_{H I i, t}$ can forecast current $R P_{L O i, t}$.

Table 7: Vector Autoregressions for the Size-Institutional Ownership Portfolios

\begin{tabular}{lllllll}
\hline Tercile & $\begin{array}{l}\text { Dependent } \\
\text { Variable }\end{array}$ & $\begin{array}{l}\text { Lag } \\
\text { Length }\end{array}$ & $\begin{array}{l}\text { Sum of } \\
\text { Coefficients }\end{array}$ & Wald (a) & Wald (b) & $\begin{array}{l}\text { HI leads } \\
\text { LO }\end{array}$ \\
\hline \multirow{2}{*}{$R$} & $R P_{L O I, t}$ & 4 & 0.406 & $7.963 * *$ & $7.532 * *$ & Yes \\
& $R P_{H I I, t}$ & 4 & 0.005 & 0.037 & & \\
2 & $R P_{L O 2, t}$ & 3 & 0.436 & $5.904 * *$ & $5.296 * *$ & Yes \\
\hline
\end{tabular}

\footnotetext{
${ }^{22}$ We find that the ranking of stocks according to their market capitalisation and institutional ownership levels in each year of the sample period does not generally change. Therefore, if three size based terciles are formed in each year by ordering stocks according to their market capitalisation, then the same stocks will comprise the $H I$ and $L O$ portfolios in each tercile. As such, using an average of the market capitalisation and institutional ownership levels, for each stock over the sample period, provides an unambiguous depiction of lead-lag effects in the TTSE.
} 


\begin{tabular}{|c|c|c|c|c|c|c|}
\hline & $R P_{H I 2, t}$ & 3 & 0.022 & $2.928 *$ & & \\
\hline \multirow{2}{*}{3} & $R P_{L O 3, t}$ & 3 & 0.177 & $24.870 * *$ & \multirow{2}{*}{$10.432 * *$} & \multirow{2}{*}{ Yes } \\
\hline & $R P_{H I 3, t}$ & 3 & -0.135 & 2.265 & & \\
\hline
\end{tabular}

The table shows that in each size based tercile, $R P_{H I}$ leads $R P_{L O}$. Specifically, the lagged values of $R P_{H I}$ exhibit statistically significant predictive power for future returns on $R P_{L O}$. The lagged values of $R P_{L O}$ however exhibit no ability to predict future $R P_{H I}$ in two of the three terciles. Moreover, the Wald (b) test statistic for the cross-equation hypothesis that $R P_{H I}$ predicts $R P_{L O}$ better than vice versa, is statistically significant in each quintile. Overall, these results closely parallel the previous findings that stocks with a higher level of institutional investment adjust to market-wide information faster than stocks with lower institutional ownership.

\subsection{Dimson Beta Regressions}

We further investigate lead-lag effects between $H I$ and $L O$ stocks using the market model regression outlined in Dimson (1979). ${ }^{23}$ This model specifically assesses the speed of adjustment of $H I$ and $L O$ stocks to contemporaneous and lagged market-wide information. The intuition behind this model is as follows. If $H I$ leads $L O$, then $H I$ should have greater sensitivity to current market-wide information than $L O$, while $L O$ should be more responsive to lagged market-wide information than $H I$.

To illustrate this model, consider a zero net investment stock $O$, which is long in stock $H I$ and short in stock $L O$. The returns of $O$ are constructed as the difference between the returns of

\footnotetext{
${ }^{23}$ Prior studies that use the Dimson (1979) market model for assessing the speed of adjustment hypothesis include Brennan et al. (1993), Chordia and Swaminathan (2000) and Park and Chung (2007).
} 
$H I$ and $L O\left(R_{O}=R_{H I}-R_{L O}\right)$. As a proxy of market wide information, the model uses the returns of an equally weighted market portfolio $\left(R_{M P}\right) \cdot{ }^{24} R_{O}$ is regressed on the leads, lags and contemporaneous $R_{M P}$ as follows:

$$
R_{O, t}=\alpha_{O}+\sum_{k=1}^{K} \beta_{O, k} R_{M P, t-k}+\beta_{O, 0} R_{M P, t}+\sum_{k=1}^{K} \beta_{O, k} R_{M P, t+k}+v_{t}
$$

where $\beta_{O, k}=\beta_{H I, k}-\beta_{L O, k}$. Stock $H I$ adjusts to market-wide information faster than stock $L O$ if: (1) the contemporaneous beta of stock $H I, \beta_{H I, 0}$, is greater than the contemporaneous beta of stock $L O, \beta_{L O, 0}$, and (2) the sum of the lagged betas of stock $H I, \sum_{K=1}^{k} \beta_{H I, t-k}$, is less than the sum of the lagged betas of stock $L O, \sum_{K=1}^{k} \beta_{L O, t-k}$. In terms of equation (4), this translates into testing whether (1) the contemporaneous coefficient $\beta_{O, 0}$ is positive and statistically significant, and (2) the sum of the lagged coefficients $\sum_{k=1}^{K} \beta_{O, k, t-k}$ is negative and statistically different from zero. If $H I$ has a faster speed of adjustment than $L O$, then its sensitivity to current market-wide information $\left(R_{M P}\right)$ should be higher than that of $L O$. Therefore, we expect that the contemporaneous coefficient of the zero investment stock should be positive, that is, $\beta_{O, 0}=\left(\beta_{H I, 0}-\beta_{L O, 0}\right)>0$. Moreover, if $L O$ responds slowly to current information, it should have a greater sensitivity to historical market-wide information (lagged $M P$ ) relative to $H I$. Therefore, we expect the sum of the lagged betas of the zero investment stock to be negative, that is, $\sum_{k=1}^{K} \beta_{O, k, t-k}<0$. To this end, $H I$ leads $L O$ provided that $\beta_{O, 0}>0$ and $\sum_{k=1}^{K} \beta_{O, k, t-k}<0$. Similar to the VAR methodology, we examine the restriction $\sum_{k=1}^{K} \beta_{O, k, t-k}<0$ using a Wald test.

\footnotetext{
${ }^{24}$ The market portfolio is constructed by taking an average of the returns of all stocks traded on the TTSE.
} 
Table 8 provides the results of the Dimson (1979) market model regression for each size based quintile. Similar to the VAR methodology, the lag length in each regression is selected using the AIC and SIC. The sum of the coefficients provided is the sum of the lag and lead betas of the zero net investment stock in equation (4), namely $\sum_{k=1}^{K} \beta_{O, k, t-k}$ and $\sum_{k=1}^{K} \beta_{O, k, t+k}$ respectively. The contemporaneous coefficient denotes $\beta_{O, 0}$ from equation (4).

Table 8: Dimson Beta Regressions for the Size-Institutional Ownership

\begin{tabular}{|c|c|c|c|c|c|c|}
\hline \multirow{2}{*}{ Quintile } & \multirow{2}{*}{$\begin{array}{l}\text { Dependent } \\
\text { Variable }\end{array}$} & \multirow{2}{*}{$\begin{array}{l}\text { Lag } \\
\text { Length }\end{array}$} & \multicolumn{2}{|c|}{ Sum of Coefficients } & \multirow{2}{*}{$\begin{array}{l}\text { Contemporaneous } \\
\text { Coefficient }\end{array}$} & \multirow{2}{*}{$\begin{array}{l}\text { HI leads } \\
L O\end{array}$} \\
\hline & & & Lags & Leads & & \\
\hline 1 & $R_{O 1, t}$ & 4 & $-0.321 * *$ & $0.229 * *$ & $0.147 * *$ & Yes \\
\hline 2 & $R_{O 2, t}$ & 4 & $-0.519 * *$ & $0.472 * *$ & $0.125^{*}$ & Yes \\
\hline 3 & $R_{O 3, t}$ & 3 & $-0.278 * *$ & $0.222 * *$ & $0.114 * *$ & Yes \\
\hline 4 & $R_{O 4, t}$ & 4 & $-0.360 * *$ & $0.293 * *$ & $0.211 * *$ & Yes \\
\hline 5 & $R_{O 5, t}$ & 5 & $-0.222 * *$ & $0.581 * *$ & $0.484 * *$ & Yes \\
\hline
\end{tabular}

Note: $* *$ and $*$ to statistical significance at the 5\% and $10 \%$ level. The lag length in each regression is selected on the basis of the Akaike (1974) and Schwartz (1978) information criteria. The sum of the coefficients reported are the sum of the lagged betas, $\sum_{k=1}^{K} \beta_{O, k, t-k}$, and the sum of the lead betas $\sum_{k=1}^{K} \beta_{O, k, t-k}$ in equation (4). The contemporaneous coefficient refers to $\beta_{O, 0}$ in equation (1). If the $R_{H I}$ has a faster speed of adjustment, and therefore leads $R_{L O}$, then the following restrictions must be fulfilled: (1) $\beta_{O, 0}$ must be positive and statistically significant, and (2) $\sum_{k=1}^{K} \beta_{O, k, t-k}$ must be negative and statistically significantly different from 0 .

The results provide strong evidence that $H I$ leads $L O$, which support the initial findings of the VAR in Table 5. In each size quintile, the contemporaneous beta $\beta_{O, 0}$ is positive and statistically significant, suggesting that $H I$ stocks are more sensitive to current market-wide information than $L O$ stocks. Also, the sum of the lag coefficients $\sum_{k=1}^{K} \beta_{O, k, t-k}$ is negative and statistically different from zero in each size quintile, implying that $L O$ stocks are more 
responsive to historical market-wide information. Overall, these results indicate that the returns on the $H I$ stocks adjust faster to market-wide information, and therefore lead the returns of $L O$ stocks.

We also note that in each quintile, the sum of the leading coefficients, $\sum_{k=1}^{K} \beta_{O, k, t+k}$, are significantly different from zero. Chordia and Swaminathan (2000), point out that such results indicate $H I$ stocks are able to predict (lead) the future returns of the equally weighted market portfolio. This lends support to the findings of lead-lag effects between $H I$ stocks and $M P$ provided in Table 9.

Table 9: Dimson Beta Regressions for the Size-Institutional Ownership (Portfolios)

\begin{tabular}{|c|c|c|c|c|c|c|}
\hline Quintile & $\begin{array}{l}\text { Dependent } \\
\text { Variable }\end{array}$ & $\begin{array}{l}\text { Lag } \\
\text { Length }\end{array}$ & $\begin{array}{l}\text { Sum of } \\
\text { Coefficients }\end{array}$ & Wald (a) & $\begin{array}{l}\text { Wald } \\
\text { (b) }\end{array}$ & $H I$ leads $M P$ \\
\hline \multirow{2}{*}{1} & $R_{M P, t}$ & 4 & 0.232 & $34.659 * *$ & \multirow{2}{*}{$4.840 * *$} & \multirow{2}{*}{ Yes } \\
\hline & $R_{H I l, t}$ & 4 & -0.080 & 2.017 & & \\
\hline \multirow{2}{*}{2} & $R_{M P, t}$ & 2 & 0.360 & $42.971 * *$ & \multirow{2}{*}{$18.986 * *$} & \multirow{2}{*}{ Yes } \\
\hline & $R_{H I 2, t}$ & 2 & 0.107 & $31.909 * *$ & & \\
\hline \multirow{2}{*}{3} & $R_{M P, t}$ & 3 & 0.111 & $28.825 * *$ & \multirow{2}{*}{$8.568 * *$} & \multirow{2}{*}{ Yes } \\
\hline & $R_{H I 3, t}$ & 3 & 0.027 & 0.516 & & \\
\hline \multirow{2}{*}{4} & $R_{M P, t}$ & 3 & 0.125 & $12.791 * *$ & \multirow{2}{*}{$4.396 * *$} & \multirow{2}{*}{ Yes } \\
\hline & $R_{H I 4, t}$ & 3 & 0.034 & 0.134 & & \\
\hline \multirow{2}{*}{5} & $R_{M P t}$ & 5 & 0.219 & $17.191 * *$ & \multirow{2}{*}{$6.667 * *$} & \multirow{2}{*}{ Yes } \\
\hline & $R_{H I 5, t}$ & 5 & 0.112 & $6.021 * *$ & & \\
\hline
\end{tabular}

Note: $* *$ and $*$ to statistical significance at the $5 \%$ and $10 \%$ level. See also notes for Table 8.

\section{Conclusions}

In this paper we consider whether differences in the level of institutional investment across firms can give rise to lead-lag cross-autocorrelations in an embryonic equity market setting. We use firm level data from TTSE for the embryonic stage of development of this emerging 
equity market, one which experienced a high level of institutional investment over the period of investigation. In addition, its microstructures, regulatory and information environments are under-developed, making it an ideal setting to assess lead-lag relations in an emerging market context. The use of firm level data enables us to accurately represent the pattern of lead-lag effects between stocks with different institutional ownerships, which could otherwise be hidden if only portfolio level data were used.

We apply this data in a vector autoregression (VAR) framework and find that the level of institutional ownership among stocks is a significant determinant of lead-lag crossautocorrelation in stock returns. Specifically, the returns of stocks with a high level of institutional ownership have substantial predictive power and lead the returns of stocks with a low institutional ownership. We attribute this result to the tendency of stocks with a low level of institutional ownership to react to information more slowly than the high institutional ownership stocks. Such results are consistent with previous studies that explored whether lead-lag effects arise due to differences in institutional investments across portfolios in the NYSE (see Bardinath et al., 1995; Sias and Starks, 1997; Chuang and Lee; 2011). This suggests the level of institutional investment in equities can influence the speed of adjustment and give rise to lead-lag effects in international stock markets, regardless of whether they are developed or emerging (even in their very early stages of development). We also show that the returns of the high institutionally owned stocks lead the returns of the TTSE market portfolio. This suggests that the high institutionally owned stocks adjust to information faster than the aggregate market portfolio. By contrast, the market portfolio returns are found to lead the returns on the low institutionally owned stocks, indicating that the speed of adjustment of the low institutionally owned stocks is lower than that of the market portfolio. 
Additional analysis reveals that, unlike developed stock markets where high institutional coverage tends to be associated with high liquidity levels, the degree of institutional ownership in TTSE still accounts for lead-lag relationships under the prevailing, relatively illiquid market conditions. Further, we show that an increase in the liquidity of high institutionally owned stocks can improve the extent to which the returns on these stocks lead the returns on the low institutionally owned stocks. This is presumably because an increase in the liquidity of the high institutionally owned stocks tends to improve the speed of adjustment to information advantages. The extent to which the high institutionally owned stocks lead the returns of the low institutionally owned stocks is shown to be tempered also by the liquidity of the low institutionally owned stocks. Again this finding is consistent with the speed of adjustment of low institutionally favoured stocks to prior changes in the returns of high institutionally owned stocks increasing with increase in the liquidity of these stocks. This indicates that liquidity effects condition, but do not account for, the institutional ownership effect, and provides support for a separate informational effect associated with institutional ownership.

The findings have important implications for informational efficiency. First, evidence of cross-autocorrelation among stocks indicates return predictability. In particular, the returns of the low institutionally owned stocks and the equally weighted market portfolio can be predicted using the past returns of the high institutionally owned stocks. This predictability is a clear violation of the defining property of market efficiency, which is the unpredictability of stock price increments. Second, the returns of the high institutionally owned stocks lead the returns on the low institutionally owned stocks and the market portfolio. This implies that the high institutionally owned stocks adjust faster to information than the low institutionally 
owned stocks and the market portfolio. ${ }^{25}$ This is because institutional investors tend to actively gather information on the stocks they invest in. As such, they are able to revise their valuations of the stocks which they hold and their trading will reflect this information quickly. Individual investors, however, tend to gather less information than institutional investors. Therefore, the price adjustment of the high institutionally owned stocks would be faster than that of the stocks that are mostly held by individual investors. This suggests that the high institutionally owned stocks are more informational efficient than the low institutionally owned stocks.

\section{References}

Badrinath, S., Kale, J., Noe, T., 1995. Of shepherds, sheep and the cross- autocorrelations in equity returns. Review of Financial Studies 8, 401-430.

Bae, K.-H., Ozoguz, A., Tan, H., Wirjanto, T., 2012. Do foreigners facilitate information transmission in emerging markets? Journal of Financial Economics 105, 209-227.

Bekaert, G., Harvey, C., 2002. Research in emerging market finance: looking to the future. Emerging Markets Review 4, 429-448.

Bekaert, G., Harvey, C., 2003. Emerging markets finance. Journal of Empirical Finance 10, 3-55.

Blume, L., Easley, D., O'Hara, M. 1994. Market statistics and technical analysis: the role of volume. Journal of Finance 49, 153-181.

Bohl, M., Brzeszczyński, J., 2006. Do institutional investors destabilize stock prices? Evidence from an emerging market. Journal of International Financial Markets, Institutions and Money 16, 370-383

Bohl, M., Salm, C., Schuppli M., (2011) Price discovery and investor structure in stock index futures. Journal of Futures Markets. 31, 282-306.

Boudoukh, J., Richardson, M., Whitelaw, R., 1994. A tale of three schools: Insights on autocorrelations of short-horizon stock returns. Review of Financial Studies 7, 539-573.

${ }^{25}$ Brennan et al. (1993) provide a theoretical proof of this. 
Boyer, B., Kumagai, Y., 2006. How do crises spread? Evidence from accessible and inaccessible stock indices. Journal of Finance 61, 957-1003.

Brennan, M., Jegadeesh, N., Swaminathan, B., 1993. Investment analysis and the adjustment of stock prices to common information. Review of Financial Studies 6, 799-824.

Brennan, M., Chordia, T., Subrahmanyam, A., 1998. Alternative factor specifications, security characteristics, and the cross-section of expected stock returns. Journal of Financial Economics 49, 345-373.

Chan, K., Hameed, A., 2006. Stock price synchronicity and analyst coverage in emerging markets. Journal of Financial Economics 80, 115-147.

Chan, K., Menkveld, A.J., Yang, Z., 2007. The informativeness of domestic and foreign investors' stock trades: evidence from the perfectly segmented Chinese market. Journal of Financial Markets 10, 391-415.

Chordia, T., Swaminathan, B., 2000. Trading volume and cross-autocorrelations in stock returns. Journal of Finance 55, 913-935.

Chuang, W., Lee, B., 2011. The informational role of institutional investors and financial analysts in the market. Journal of Financial Markets 14, 465-493.

Datar, V., Naik, N., Radcliffe, R., 1998, Liquidity and stock returns: an alternative test. Journal of Financial Markets 1, 203-219.

Gallant, R., Rossi, P., Tauchen, G., 1992. Stock prices and volume. Review of Financial Studies 5, 199-242.

Gebka, B., 2008. Volume- and size-related lead-lag effects in stock returns and volatility: An empirical investigation of the Warsaw Stock Exchange International Review of Financial Analysis 17, $134-155$.

Hameed, A., 1997. Time-varying factors and cross-autocorrelations in short-horizon stock returns. Journal of Financial Research 20, 435- 458.

Harris, L., 2002. Trading and Exchanges: Market Microstructures for Practitioners. Oxford: Oxford University Press.

Hiemstra, C., Jones, J., 1994. Testing for linear and nonlinear Granger causality in the stock price volume relation. Journal of Finance 49, 1639-1664. 
Hou, K., 2007. Industry information diffusion and the lead-lag effect in stock returns. Review of Financial Studies 20, 1113 - 1138.

Jennings, R., Starks, L., Fellingham, J., 1981. An equilibrium model of asset trading with sequential information arrival. Journal of Finance 36, 143-162.

Jones, C., Kaul. G., Lipson, M., 1994. Transactions, volume, and volatility. Review of Financial Studies 7, 631-651.

Lo, A., MacKinlay, A., 1990. When are contrarian profits due to stock market overreaction. Review of Financial Studies 3, 175-206.

Merton, R., 1987. A simple model of capital market equilibrium with incomplete information. Journal of Finance 42, 483-510.

Næs, R., Skjeltorp, J., 2003. Equity trading by institutional investors. Evidence on order submission strategies. Journal of Banking and Finance 27, 1779-1817.

Park, Y., Chung, K., 2007. Foreign and Local Institutional Ownership and the Speed of Price Adjustment. Journal of Business Finance \& Accounting, 34, 1569-1595.Rubin, A., 2007. Ownership level, ownership concentration and liquidity. Journal of Financial Markets 10, 219-248.

Poshakwale, S., Theobald, M., 2004. Market capitalisation, cross-correlations, the lead/lag structure and microstructure effects in the Indian stock market. International Financial Markets, Institutions and Money 14, 385-400.

Sias, R., Starks, L., 1997. Return autocorrelation and institutional investors. Journal of Financial Economics 46, 103-131.

Syriopoulos, T., 2006. Risk and return implications from investing in emerging European stock markets. International Financial Markets, Institutions and Money 16, 283-299.

$\mathrm{Xu}$, N., Chan, K., Jiang,X. Yi, Z., Do star analysts know more firm-specific information? Evidence from China? Journal of Banking \& Finance 37, 89-102. 


\section{Appendix Tables}

Table A.1: Scale of Trading Activity on the TTSE.

\begin{tabular}{lllll}
\hline \hline & $\begin{array}{l}\text { Listed } \\
\text { Securities }\end{array}$ & $\begin{array}{l}\text { Market } \\
\text { Capitalisation } \\
\text { (USD Millions) }\end{array}$ & $\begin{array}{l}\text { Average Daily } \\
\text { Turnover \% }\end{array}$ & $\begin{array}{l}\text { Average Daily } \\
\text { Equity Volume } \\
\text { Traded (000's) }\end{array}$ \\
\hline $\mathbf{2 0 0 1}$ & 30 & $\$ 5,082.82$ & 3.289 & 837 \\
$\mathbf{2 0 0 2}$ & 30 & $\$ 7,695.88$ & 2.204 & 648 \\
$\mathbf{2 0 0 3}$ & 32 & $\$ 10,876.73$ & 3.388 & 2787 \\
$\mathbf{2 0 0 4}$ & 34 & $\$ 17,209.61$ & 2.804 & 2052 \\
$\mathbf{2 0 0 5}$ & 34 & $\$ 17,200.59$ & 3.645 & 1290 \\
$\mathbf{2 0 0 6}$ & 33 & $\$ 15,494.13$ & 2.544 & 1441 \\
$\mathbf{2 0 0 7}$ & 33 & $\$ 15,708.36$ & 2.178 & 817 \\
$\mathbf{2 0 0 8}$ & 34 & $\$ 12,229.26$ & 2.867 & 605 \\
$\mathbf{2 0 0 9}$ & 33 & $\$ 11,292.18$ & 2.089 & 310 \\
$\mathbf{2 0 1 0}$ & 32 & $\$ 12,444.95$ & 1.112 & 314 \\
$\mathbf{2 0 1 1}$ & 31 & $\$ 15,115.41$ & 1.089 & 2293 \\
$\mathbf{2 0 1 2}$ & 32 & $\$ 19,001.11$ & 0.632 & 211 \\
& & & & \\
\hline \hline
\end{tabular}


Table A.2: Summary Information on Regional Embryonic Stock Markets (2012)

\begin{tabular}{llll}
\hline \hline Country & $\begin{array}{l}\text { Listed } \\
\text { Domestic } \\
\text { Companies }\end{array}$ & $\begin{array}{l}\text { Market } \\
\text { Capitalisation } \\
\text { (\% of GDP) }\end{array}$ & $\begin{array}{l}\text { Turnover Ratio } \\
\%\end{array}$ \\
\hline Trinidad \& Tobago & 32 & 65 & 0.8 \\
Barbados & 24 & 106 & 0.4 \\
Bermuda & 13 & 27 & 2.0 \\
Bolivia & 40 & 16 & 0.5 \\
Colombia & 76 & 71 & 11.2 \\
Costa Rica & 9 & 5 & 1.9 \\
Ecuador & 45 & 7 & 2.3 \\
El Salvador & 64 & 45 & 0.6 \\
Jamaica & 36 & 43 & 3.0 \\
Panama & 25 & 35 & 1.0 \\
Paraguay & 62 & 4 & 5.5 \\
Venezuela & 41 & 7 & 0.2 \\
& & & \\
\hline \hline
\end{tabular}

Notes: The data presented in the table are based on embryonic stock markets from the Latin American and Caribbean region with less than 100 listed domestic companies in 2012. Market capitalisation is the average annual market valuation expressed as a $\%$ of GDP. The turnover ratio is the total value of shares traded during the year expressed as a $\%$ of the average annual market capitalisation.

Source: World Development Indicators and own data 
Table A.3: Firms Listed on the TTSE

\section{Banking Stocks}

BCB Holdings Limited

First Caribbean International Bank Limited

National Commercial Bank Jamaica Limited

Republic Bank Limited

Scotiabank Trinidad and Tobago Limited

\section{Conglomerates Stocks}

ANSA McAl Limited Barbados Shipping and Trading Company Limited

Grace Kennedy Limited

Neal and Massy Holdings Limited

Property - PLIPDECO Limited

\section{Manufacturing Stocks}

Angostura Holdings Limited

Guardian Media Limited

National Flour Mills Limited

One Caribbean Media Limited

The West Indian Tobacco Company Limited

Unilever Caribbean Limited

Berger Paints Trinidad Limited

Flavorite Foods Limited

Readymix (West Indies) Limited

Trinidad Cement Limited

\section{Trading Stocks}

Agostini Limited

LJ Williams Limited

Prestige Holdings Limited

Supreme Ventures Limited

\section{Non-Banking Finance Stocks}

ANSA Merchant Bank Limited

Capital \& Credit Financial Group Limited

Guardian Holdings Limited

Jamaica Money Market Brokers Limited

National Enterprises Limited

Sagicor Financial Corporation

Scotia Investments Jamaica Limited

\section{Other Stocks}

Mora Ven Holdings Limited 
Table A.4: Vector Autoregressions for the Size-High Institutional Ownership Stocks and the Market Portfolio

\begin{tabular}{|c|c|c|c|c|c|c|}
\hline Quintile & $\begin{array}{l}\text { Dependent } \\
\text { Variable }\end{array}$ & $\begin{array}{l}\text { Lag } \\
\text { Length }\end{array}$ & $\begin{array}{l}\text { Sum of } \\
\text { Coefficients }\end{array}$ & Wald (a) & $\begin{array}{l}\text { Wald } \\
\text { (b) }\end{array}$ & $H I$ leads $M P$ \\
\hline \multirow{2}{*}{1} & $R_{M P, t}$ & 4 & 0.232 & $34.659 * *$ & \multirow{2}{*}{$4.840 * *$} & \multirow{2}{*}{ Yes } \\
\hline & $R_{H I I, t}$ & 4 & -0.080 & 2.017 & & \\
\hline \multirow{2}{*}{2} & $R_{M P, t}$ & 2 & 0.360 & $42.971 * *$ & \multirow{2}{*}{$18.986 * *$} & \multirow{2}{*}{ Yes } \\
\hline & $R_{H I 2, t}$ & 2 & 0.107 & $31.909 * *$ & & \\
\hline \multirow{2}{*}{3} & $R_{M P, t}$ & 3 & 0.111 & $28.825 * *$ & \multirow{2}{*}{$8.568 * *$} & \multirow{2}{*}{ Yes } \\
\hline & $R_{H I 3, t}$ & 3 & 0.027 & 0.516 & & \\
\hline \multirow{2}{*}{4} & $R_{M P, t}$ & 3 & 0.125 & $12.791 * *$ & \multirow{2}{*}{$4.396 * *$} & \multirow{2}{*}{ Yes } \\
\hline & $R_{H I 4, t}$ & 3 & 0.034 & 0.134 & & \\
\hline \multirow{2}{*}{5} & $R_{M P t}$ & 5 & 0.219 & $17.191 * *$ & \multirow{2}{*}{$6.667 * *$} & \multirow{2}{*}{ Yes } \\
\hline & $R_{H I 5, t}$ & 5 & 0.112 & $6.021 * *$ & & \\
\hline
\end{tabular}

Note: $* *$ and $*$ indicate statistical significance at the $5 \%$ and $10 \%$ levels respectively. See also notes for Table 5 . 
Table A.5: Vector Autoregressions for the Size-Low Institutional Ownership Stocks and the Market Portfolio

\begin{tabular}{|c|c|c|c|c|c|c|}
\hline Quintile & $\begin{array}{c}\text { Dependent } \\
\text { Variable }\end{array}$ & $\begin{array}{c}\text { Lag } \\
\text { Length }\end{array}$ & $\begin{array}{c}\text { Sum of } \\
\text { Coefficients }\end{array}$ & Wald (a) & Wald (b) & $\begin{array}{c}M P \text { leads } \\
L O\end{array}$ \\
\hline \multirow{2}{*}{1} & $R_{L O 1, t}$ & 4 & 0.342 & $5.499 * *$ & \multirow{2}{*}{$3.420 *$} & \multirow{2}{*}{ Yes } \\
\hline & $R_{M P 1, t}$ & 4 & 0.076 & $40.807 * *$ & & \\
\hline \multirow{2}{*}{2} & $R_{L O 2, t}$ & 4 & 0.634 & $38.301 * *$ & \multirow{2}{*}{$35.898 * *$} & \multirow{2}{*}{ Yes } \\
\hline & $R_{M P 2, t}$ & 4 & 0.026 & $3.837^{*}$ & & \\
\hline \multirow{2}{*}{3} & $R_{L O 3, t}$ & 4 & 0.271 & $4.057 * *$ & \multirow{2}{*}{0.013} & \multirow{2}{*}{ No } \\
\hline & $R_{M P 3, t}$ & 4 & 0.022 & 2.573 & & \\
\hline \multirow{2}{*}{4} & $R_{L O 4, t}$ & 4 & 0.516 & $32.781 * *$ & \multirow{2}{*}{$31.160 * *$} & \multirow{2}{*}{ Yes } \\
\hline & $R_{M P 4, t}$ & 4 & 0.045 & $33.263^{* *}$ & & \\
\hline \multirow{2}{*}{5} & $R_{L O 5, t}$ & 4 & 0.251 & $7.274 * *$ & \multirow{2}{*}{$9.598 * *$} & \multirow{2}{*}{ Yes } \\
\hline & $R_{M P 5, t}$ & 4 & 0.054 & 0.021 & & \\
\hline
\end{tabular}

Note: $* *$ and $*$ indicate statistical significance at the 5\% and $10 \%$ levels respectively. See also notes for Table 5. 
Table A.6: Impact of Liquidity on Cross-autocorrelation (Robustness Check)

\begin{tabular}{|c|c|c|}
\hline Equation (1) & Sum of Coefficients & Wald Test \\
\hline \multicolumn{3}{|c|}{ Panel A: (Quintile 1) Dependent Variable $-R_{L O 1, t}$} \\
\hline$R_{L O 1, t}$ & 0.234 & $59.709 * *$ \\
\hline$R_{H I 1, t-k}$ & 0.288 & $8.297 * *$ \\
\hline$L i q_{H I 1, t-k}$ & 0.601 & 1.107 \\
\hline $\operatorname{Liq}_{L O 1, t-k}$ & 0.264 & 1.020 \\
\hline$R_{H I 1, t-k} * L_{i} q_{H I 1, t-k}$ & 79.868 & $9.008 * *$ \\
\hline$R_{H I 1, t-k} * \operatorname{Liq}_{L O 1, t-k}$ & -125.806 & $27.793 * *$ \\
\hline \multicolumn{3}{|c|}{ AIC $/ \mathrm{SIC}=3$ Joint test $=205.192 * *$ Adj- $\mathrm{R}^{2}=0.071$} \\
\hline \multicolumn{3}{|c|}{ *Panel B: (Quintile 2) Dependent Variable $-\boldsymbol{R}_{L O 2, t}$} \\
\hline$R_{L O 2, t}$ & 0.190 & $31.945^{* *}$ \\
\hline$R_{H I 2, t-k}$ & 0.626 & $94.882 *$ \\
\hline $\operatorname{Liq}_{H I 2, t-k}$ & -0.994 & 0.144 \\
\hline $\operatorname{Liq}_{L O 2, t-k}$ & 0.602 & $9.355 * *$ \\
\hline$R_{H I 2, t-k} * L i q_{H I 2, t-k}$ & 455.113 & $13.529 * *$ \\
\hline$R_{H I 2, t-k} * L_{L i q}{ }_{L O 2, t-k}$ & -494.314 & $16.260 * *$ \\
\hline \multicolumn{3}{|c|}{ AIC/SIC $=3$ Joint test: Wald $=442.152 * *$ Adj $-R^{2}=0.148$} \\
\hline \multicolumn{3}{|c|}{ Panel C: (Quintile 3) Dependent Variable $-R_{L O 3, t}$} \\
\hline$R_{L O 3, t}$ & 0.176 & $28.144 * *$ \\
\hline$R_{H I 3, t-k}$ & 0.319 & $10.636 * *$ \\
\hline$L i q_{H I 3, t-k}$ & 0.289 & 0.712 \\
\hline $\operatorname{Liq}_{L O 3, t-k}$ & 0.982 & $3.134 *$ \\
\hline$R_{H I 3, t-k} * L_{i q} q_{H I 3, t-k}$ & 68.039 & $4.180 * *$ \\
\hline$R_{H I 3, t-k} * \operatorname{Liq}_{L O 3, t-k}$ & -62.817 & $3.398 *$ \\
\hline \multicolumn{3}{|c|}{ AIC/SIC $=3$ Joint test: Wald $=245.802 * * A d j-R^{2}=0.186$} \\
\hline \multicolumn{3}{|c|}{ Panel D: (Quintile 4) Dependent Variable - $\boldsymbol{R}_{L O 4 . t}$} \\
\hline$R_{L O 4, t}$ & -0.453 & $77.029 * *$ \\
\hline$R_{H I 4, t-k}$ & 0.475 & $4.661 * *$ \\
\hline$L i q_{H I 4, t-k}$ & 0.377 & 0.276 \\
\hline $\operatorname{Liq}_{L O 4, t-k}$ & 4.876 & $4.770 * *$ \\
\hline$R_{H I 4, t-k} * L_{i q} q_{H 4, t-k}$ & -801.793 & $21.906 * *$ \\
\hline$R_{H I 4, t-k} * \operatorname{Liq}_{L O 4, t-k}$ & -2277.133 & $18.714 * *$ \\
\hline \multicolumn{3}{|c|}{ AIC/SIC $=4$ Joint test: Wald $=584.782 * *$ Adj- $\mathrm{R}^{2}=0.227$} \\
\hline \multicolumn{3}{|c|}{ Panel E: (Quintile 5) Dependent Variable - $\boldsymbol{R}_{L O 5, t}$} \\
\hline$R_{L O 5, t}$ & 0.281 & $77.310 * *$ \\
\hline$R_{H I 5, t-k}$ & 0.192 & $16.571 * *$ \\
\hline $\operatorname{Liq}_{H I 5, t-k}$ & -0.193 & 0.514 \\
\hline $\operatorname{Liq}_{L O 5, t-k}$ & 7.547 & $4.126 * *$ \\
\hline$R_{H I 5, t-k} * \operatorname{Liq}_{H I 5, t-k}$ & 31.503 & $5.593 * *$ \\
\hline$R_{H I 5, t-k} * \operatorname{Liq}_{L O 5, t-k}$ & -82.638 & $38.411 * *$ \\
\hline
\end{tabular}

Note: ** and * indicate statistical significance at the 5\% and $10 \%$ levels respectively. For the above estimations we used stock turnover as a measure of liquidity. See also notes for Table 7. 